\title{
Editorial: crime patterns in time and space: the dynamics of crime opportunities in urban areas
}

\author{
Andrew Newton ${ }^{1 *}$ and Marcus Felson ${ }^{2}$
}

\begin{abstract}
The routine activity approach and associated crime pattern theory emphasise how crime emerges from spatio-temporal routines. In order to understand this crime should be studied in both space and time. However, the bulk of research into crime patterns and related activities has investigated the spatial distributions of crime, neglecting the temporal dimension. Specifically, disaggregation of crime by place and by time, for example hour of day, day of week, month of year, season, or school day versus none school day, is extremely relevant to theory. Modern data make such spatio-temporal disaggregation increasingly feasible, as exemplified in this special issue. First, much larger data files allow disaggregation of crime data into temporal and spatial slices. Second, new forms of data are generated by modern technologies, allowing innovative and new forms of analyses. Crime pattern analyses and routine activity inquiries are now able to explore avenues not previously available. The unique collection of nine papers in this thematic issue specifically examine spatio-temporal patterns of crime to; demonstrate the value of this approach for advancing knowledge in the field; consider how this informs our theoretical understanding of the manifestations of crime in time and space; to consider the prevention implications of this; and to raise awareness of the need for further spatio-temporal research into crime events.
\end{abstract}

Keywords: Crime patterns; Spatio-temporal analysis; Crime opportunities; Routine activities; Dynamic hot spots

\section{Introduction}

The distribution of crime is not random in time and space. Explanations for this are grounded in routine activities theory (Cohen and Felson 1979) and crime pattern theory (Brantingham and Brantingham 1981). In 'simple' terms; the occurrence of a crime requires the juxtaposition of motivated offenders and suitable targets, a situation constrained in time and space. These constraints are defined by an offenders and victims use of time and space, as their activities are bounded by the need to eat, sleep, work, or for recreational activity. Moreover, these activities can only occur at a finite number of locations and times; and, that the movement of offenders and victims is not compulsive, but structured, regulated by the daily routines of offenders and victims, and the social and physical environments within which they interact (Brantingham and Brantingham 2013). Indeed, "a limited number of sites, times, and situations constitute the space-time loci for the vast majority of offenses" (p540).

\footnotetext{
* Correspondence: a.d.newton@hud.ac.uk

${ }^{1}$ The Applied Criminology Centre, HHR2/10, The University of Huddersfield, Queensgate, Huddersfield, UK

Full list of author information is available at the end of the article
}

\section{The distribution of crime events}

The past two decades has seen a major expansion into the analysis of the spatial distribution of crime, with small scale or micro level analysis emerging at the forefront of place based research (Sherman et al. 1989; Sherman 1995; Weisburd 2015). This trend has been driven by both the increased availability of spatially referenced crime data, and the technological advances of software products which promote the analysis of the spatial clustering of crime, or hot-spot analysis. However, this growth in spatial analysis is perhaps not reflected by similar advances in the temporal analysis of crime. Whilst a number of studies have examined the temporal patterns of crime (Ashby and Bowers 2013), these are not as prominent in the field as the spatial literature. As highlighted over 10 years ago, whilst the spatial analysis of crime has thrived, analysis of the temporal distribution of crime has failed to keep pace (Ratcliffe 2002). This is still true today; "the majority of studies linking potentially criminogenic places to elevated levels of crime across geographical units have been atemporal" (Haberman and Ratcliffe in press). 
As a consequence of this, and perhaps compounded by the challenges of employing complex spatio-temporal analysis methods (Ratcliffe 2010), the inextricable link between space and time is often omitted from placebased or temporal-based crime research. With the exceptions perhaps of the near repeat victimisation literature (Johnson et al. 2007), animated visualisations of sequences of hotspots over the course of the day (Brunsdon et al. 2007; Townsley 2008), and some isolated studies now discussed, there is a paucity of research into the patterns and manifestations of crime events in both space and time.

\section{Spatio-temporal crime analysis}

Several researchers acting independently, using data on different crimes, and from different nations, have found that crime hotspots shift quickly in response to the structure of daily life. For example, major shifts have been found in robbery locations from afternoon to early morning, and weekday to weekend within the vicinity of schools, parks and late night business (Adams et al. 2015). Others have found high crime risk in some entertainment districts in the early evening, while other entertainment districts experience more crime problems after midnight. Crime near bars and pubs is significant on weekends, but such clustering may be barely noticeable on weekdays (Newton and Hirschfield 2009; Grubesic and Pridemore 2011). Crime on transit systems have been shown to be highly dynamic and related to surrounding environs with distinct patterns in both space and in time (Ceccato and Uittenbogaard 2014; Newton et al. 2014). Shiode et al. (2015) found that within high crime areas in Chicago, different micro-scale spatiotemporal crime patterns were evident for different types of crime; drugs, robbery, burglary, and vehicle crime all had their own unique spatio-temporal crime patterns. Haberman and Ratcliffe (in press) suggest that the criminogenic nature of places is influenced by a number of factors that include; the length of time facilities are open; the consistency of use during the day, for example facilities with a steady flow of people versus those with concentrations of people at peaks and sparse use at off peak times; and unofficial use of places when they are in effect closed or recently closed.

Many of the old ideas from Chicago in the 1930s and 1940s no longer hold. Areas identified as high crime parts of towns and cities experience low and moderate levels of crime during certain time periods across several of their streets/blocks. Some areas are prone to certain crime offences at particular times of the day, but rarely does analysis consider whether these areas suffer from other crime types, either simultaneously or at another time or day of the week. Moreover, little attention is afforded to the explaining the dynamics of crime hot spots. Crime can shift rapidly over the course of a 168 hour period (1 week). Furthermore, and especially when there is mixed land-use, characteristics of these populations are likely to differ substantially from the residential population, making it difficult to calculate realistic crime rates. Are these changes driven solely by population dynamics, how is this influenced by the physical and social makeup of the environments within which these crimes occur, and, what drives this change? The purpose of this thematic issue it to bring together a range of papers on crime patterns in time and space, to examine the dynamics of crime opportunities in urban areas.

\section{Aims of the thematic series}

This thematic series aims to assemble a unique collection of papers that specifically examine the spatio-temporal patterns of crime events. Some key goals are; to raise awareness of the need for more of this type of research; to promote the value of this in advancing knowledge in the field; to inform our theoretical understanding of the manifestation of crime in time and space; to investigate how opportunities for crime are constrained by the routines and movements of offenders and victims and the social and physical environments they interact with; and to consider the prevention implications of this spatio-temporal approach.

\section{Article overview}

The papers in this thematic issue are drawn from a number of different nations, and the focus is on empirical studies that better identify the space-time patterns evident, seek explanations for such observations, and consider the response implications of the findings and the challenges for prevention. This thematic issue contains nine papers from nine different cities, three each from Canada, the United States, and the United Kingdom. The table below summarises the papers and the key contribution each of these makes (Table 1).

\section{The funnelling hypothesis?}

Felson and Boivín set the scene for this thematic issue, investigating transportation data to determine how daily spatio-temporal shifts in population impact on the crime of a city. The premise here is that daily movements in a city will follow a funnelling hypothesis; and that visitors will have a greater impact than residents on crime. Whilst the data does not enable a micro-level break down of crime in time and place, the results reveal that daily visitors have a significant impact on violence and property crime distributions compared to residents. This suggests that daily spatio-temporal shifts have a greater influence than fixed residential factors in the distribution of crime opportunities over urban space.

\section{Micro spatio-temporal crime settings}

Following on from this four papers (Herrmann IrvinErickson and La Vigne; Geoffrion, Sader, Ouellet and Boivin; 
Table $1 \mathrm{~A}$ summary of papers in the thematic issue

\begin{tabular}{|c|c|}
\hline Authors & Summary and contribution \\
\hline \multicolumn{2}{|c|}{ Daily shifts in population. The funnelling hypothesis } \\
\hline Felson and Boivín & $\begin{array}{l}\text { Visitors funnelling crime risk into particular census tracts and away from others. Visitors found to impact property and } \\
\text { violent crime more than residents. Canadian case study. }\end{array}$ \\
\hline \multicolumn{2}{|c|}{ Space-time settings and the spatial-temporal landscape (school, bars and subway stations) } \\
\hline Herrmann & $\begin{array}{l}\text { Examines timing of street robbery hot spots by hour of the day. Compares school days and none school days. Finds } \\
\text { two distinct patterns of robbery. School day 3:00 pm robbery hotspots adjacent to subway stations and schools; } \\
\text { 1:00 am non-school day robbery hotspots close to bars and subway stations. US case study. }\end{array}$ \\
\hline Irvin-Erickson and La Vigne & $\begin{array}{l}\text { Examines crimes at subway stations. Finds multiple types of crime in highly dynamic settings, considering peak versus } \\
\text { off-peak and daytime versus night-time. Evidence of stations crime acting spatio-temporally as attractors and crime } \\
\text { generators. US case study. }\end{array}$ \\
\hline $\begin{array}{l}\text { Geoffrion, Sader, Ouellet } \\
\text { and Boivín }\end{array}$ & $\begin{array}{l}\text { Data gathered over a year for a large nightclub, with aggression disaggregated by hour of evening and location } \\
\text { inside the bar. Spatio-temporal patterns of aggression evident within micro settings inside bar-room environment. } \\
\text { Canadian case study. }\end{array}$ \\
\hline Newton & $\begin{array}{l}\text { Examine stability of crime hot spots around licensed premises. Consider how crime hot spots may change to different } \\
\text { locations, to different times, or hot spots for different crime types may occur simultaneously, or at differing times of the } \\
\text { day or days of the week at the same location. Examines disorder, criminal damage and violence. UK case study. }\end{array}$ \\
\hline \multicolumn{2}{|c|}{ Understanding crime in time and space } \\
\hline Andresen and Malleson & $\begin{array}{l}\text { Examines intra-week patterns of crime in time and space. Finds unique crime patterns for differing crime types in } \\
\text { both time and space by different days of the week. For example on Saturdays, theft from vehicle increased in the } \\
\text { downtown parks and recreational park areas on, and assaults also increased in the bar districts. Canadian case study. }\end{array}$ \\
\hline Tompson and Bowers & $\begin{array}{l}\text { Seasonal patterns of street robbery by hour of day and season, taking into consideration weather, thermal comfort, } \\
\text { and likelihood that people will go out. Identifies discretionary routines more likely to be influenced by weather. } \\
\text { UK case study. }\end{array}$ \\
\hline Malleson and Andresen & $\begin{array}{l}\text { Examines risk of crime taking into account ambient population and hour of day. Identifies significant hotspots of risk } \\
\text { based on dynamics of underlying population in both time and space. UK case study. }\end{array}$ \\
\hline \multicolumn{2}{|c|}{ Preventing crime in time and space } \\
\hline Boba and Santos & $\begin{array}{l}\text { Hot spots examined by hours and degree of repetition, discussing how police can respond with that information. } \\
\text { US case study. }\end{array}$ \\
\hline
\end{tabular}

and Newton) examine crime at particular facilities, public transportation, schools, bars and nightclubs. Each considers how each of these offers specific micro-loci settings for crime, around which opportunities for crime are constrained in both time and space.

Herrmann examines street robbery, using the New York Bronx as a case study area. This analysis uses the NNh clustering technique used by a number of law enforcement agencies. Two distinct spatial patterns are found in robbery hot spots when comparing school days and nonschool days. The first set of robbery hot spots peak around 3:00 pm during school days. The second are observed during non-school days, peaking around 1:00 am. Examination of the location of these spatio-temporal hotspots reveals that the daytime robberies all cluster at places close to both schools and subway stations. The night-time robberies were found to concentrate adjacent to bars and mass transit stations. This suggests the spatio-temporal landscape is clearly influential in shaping the robbery hot spots observed.

Irvin-Erickson and La Vigne's paper analyses crime at Washington DC metro stations, a highly dynamic setting. They classify time using three temporal groupings; peak times; off-peak daytime; and, off-peak night-time hours.
Their spatio-temporal analysis reveals that stations may act as crime generators and or crime attractors, and moreover, that this is time of day, location and crime type specific. Stations that are highly connected, busy, and have high levels of crime in general, tend to have high crime rate ratios, indicating crime generator characteristics, those which create unplanned but favourable opportunities for offenders. During peak hours these stations are at greater risk of larcenies and disorderly conduct, and during non-peak day hours robbery is more prevalent. Stations that were more remote and less connected to the network were more at risk of larceny during peak hours and disorderly conduct during non-peak night-time hours. These tended to act as crime attractors, places offenders travel to due to known and expected opportunities for crime. Thus crime at subway stations was a function of a station's connectedness or remoteness, the density of people present which varied by time of day, the SES group of the area it is situated, and crime in its nearby surroundings. Moreover, there were distinct spatio-temporal patterns to crime at stations.

Geoffrion, Sader, Ouellet and Boivín investigate the spatio-temporal routine activities at perhaps the most micro-level, inside a single building, a bar. Whilst at first 
it may seem unusual to think about this environment as dynamic in time and space, the study found distinct spatio-temporal patterns of aggression present even within this localised and contained micro environment. Three distinct patterns for aggression were identified with hotspots shifting by target, in time and location, between patrons, towards bouncers, and towards barmaids. Specific hotspots were identified for each victim group, unique in both time and space, driven by their activities at different points of the evening/night-time. For example aggressive incidents between patrons at the start of the evening occurred near the bar area, then from midnight to 2:00 am on the dance floors, from 2:00 am until closing were observed back at the bar area, and then at closing time in poorly lit areas near exits. Different spatio-temporal patters were observed towards barmaids and bouncers. Thus, even within a bar environment during a single evening, crime opportunities are dynamic in time and space, driven by activities constrained both in time and in space.

Newton investigates how patterns of crime in space and time should not always be examined in the context of single crime types. Indeed, as the function and use of a place changes during the day and week, alternative types of crime may emerge. They examine crime around licensed premises, and analyse three crime types-criminal damage, violence and anti-social behaviour, as the research evidence has shown each of these to correlate with the locations of licensed premises. It is important for crime prevention to ascertain which places are hot spots for only one crime type at discrete times and places, and how hot spots for different crime types shift in location by time of day. When only one crime hot spot is present then hot spot analysis using one crime type is appropriate. However, when hot spots of different crime types are observed at different times of the day/ days of the week in the same place, and hot spots of different hot spot types are found conterminously at the same time and place, then it is necessary to consider using multiple crime type hot spot analysis. This is particularly pertinent when targeting sparse police resources in time and space.

\section{Understanding crime in time and space}

A second set of papers examine more aggregated time units to understand spatio-temporal crime patterns. Andresen and Malleson explore spatio-temporal patterns by time of day and day of week; Tompson and Bowers scrutinise how weather and seasonality influence the time and location of street robbery; and Malleson and Andresen address the issue of crime risk through the use of the ambient population. The underlying population at risk is itself dynamic, changing in time and place, and is not well represented through use of residential population as a crime denominator.
Andresen and Malleson explicitly explore how the day of week impacts on the spatial and temporal patterns of crime offences for the City of Vancouver, Canada. They investigate the intra-week patters of a range of crime types and found, as expected, increased levels of crime at weekends in certain localities. For example on Saturdays, theft from vehicle increased in the downtown parks and recreational park areas, and assaults also increased in the bar districts. However not all crime types revealed expected intra-week patterns. For example, increases in burglary in particular places were observed on Mondays. For robbery and sexual assault they did not find unique intra-week patterns. This may be due to different groups of offenders operating on different days. However, for most crime types examined there were distinctive temporal and spatial patterns observed for different days of the week.

Tompson and Bowers examine the impact on weather on the spatio-temporal patterns of street robbery. They tested two hypotheses. The first of these is that people's use of space will be influenced by extremes in weather, for example excess heat and extreme cold might limit the use of outdoor space-an essential component of street robbery-whereas unexpectedly mild or favourable weather might encourage people to venture outside. They found that wind speed and temperature did affect robbery, the adverse impact of winter corresponding with a reduction in robbery, whereas an increase in temperature led to more robberies. However, these variables interacted, as despite increased temperature an increased wind speed in summer months resulted in a decrease in robberies. Thus both variables contributed to what the author's term a person's sense of thermal comfort. The authors move beyond this with their second hypothesis, to examine how weather might impact on discretionary activities, those a person pursues through choice, as opposed to obligatory routine activities they have to do. The hypothesis here is weather will influence the spatio-temporal patterns of discretionary activities more than that of obligatory ones. Temperature, wind speed and humidity were significant predictors of robbery during the night-shift and at weekends, and rain was shown to have a negative relationship with robbery at the weekends. When travel behaviour is optional, people are less likely to venture outdoors when it is raining. Thus, weather exerts significant constraints on the space-time loci of crime opportunities, particularly outside of working hours during a person's time and space delineated discretionary routine activities.

Malleson and Andresen pose a different problem. A key component in the analysis of crime is identifying levels of risk, and crime rates are often used here. For example, identification of burglary risk on a street should take account the number of properties. Violence at night time should consider the number of persons present in the 
night-time economy. Risk of assault on a train will depend on the number of passengers. Thus the denominators of crime (crime rates) are an essential component to aid our examination of crime risk. However, when considering crime in both place and time, it is problematic to identify crime rates. Calculating accurately the true population at risk in any given place and time is vital for identification of reliable crime rates. However data on the movement of persons through areas is not routinely collected during the course of the day, and not simple to capture. Residential populations identified through census and other surveys do not accurately reflect populations in business centres during the day-time, or residential areas when most people are out at work. This paper attempts to address this, and produce an examination of the ambient population. This shift in denominators changes how we think about exposure to risk of crime, bringing back to life the classic work of Sarah Boggs (1965). This paper makes use of new 'crowd sourced' data, to create better estimates of populations at risk for crimes such as street robbery, which are referenced both in place and in time. From this, through the use of spatio-temporal cluster hunting techniques, crime hot spots are identified that are significant in time and space, after taking account of the size of the estimated ambient population in the area at the time of the crime.

\section{Preventing crime in time and space}

The final paper in this thematic issue demonstrates how spatio-temporal elements of crime events are necessary for developing timely police interventions and responses. This paper examines the micro-time hot spot, a flare up of crime defined as the emergence of several closelyrelated crimes within a few minutes travel distance from one another, within a 1 to 2 week period. These are distinguished from longer term hot spots which remain stable over time. The authors find evidence that when responses to micro-time hot spots are rapid and consistent, for example over a period of 14 days, the number of subsequent crimes were reduced. The findings support the recommendation that police should act immediately when a micro time hotspot is identified, and therefore spatio-temporal analysis should be routinely conducted as part of their operation analysis tools.

\section{Competing interests}

The authors declare they have no competing interests.

\section{Authors' contributions}

AN led on the writing of the editorial introduction, and editing the nine papers submitted to the thematic issue. MF supported both the writing and the editing process. Both authors read and approved the final manuscript.

\section{Author details}

${ }^{1}$ The Applied Criminology Centre, HHR2/10, The University of Huddersfield, Queensgate, Huddersfield, UK. ${ }^{2} 109$ Hill House, Hines Academic Center, Texas State University, 601 University Dr, San Marcos, TX 78666, USA.
Received: 4 June 2015 Accepted: 4 June 2015

Published online: 24 June 2015

\section{References}

Adams, W, Herrmann, C, \& Felson, M. (2015). Crime, transportation and malignant mixes. In V Ceccato \& A Newton (Eds.), Safety and security in transit environments: an interdisciplinary perspective (pp. 181-195). Basingstoke, Hampshire: Palgrave McMillan.

Ashby, A, \& Bowers, K. (2013). A comparison of methods for temporal analysis of aoristic crime. Crime Science, 2, 1.

Boggs, S. (1965). Urban crime patterns. American Sociological Review, 30(6), 899-908.

Brantingham, PL, \& Brantingham, PJ. (1981). Notes on the geometry of crime. In PJ Brantingham \& PL Brantingham (Eds.), Environmental criminology (pp. 27-54). Prospect Heights IL: Waveland Press.

Brantingham, PL, \& Brantingham, PJ. (2013). The theory of target search. In F Cullen \& P Wilcox (Eds.), The Oxford handbook of criminological theory (pp. 535-553). New York, NY: Oxford University Press.

Brunsdon, C, Corcoran, J, \& Higgs, G. (2007). Visualising space and time in crime patterns: a comparison of methods. Computers, Environment and Urban Systems, 31, $52-75$.

Ceccato, V, \& Uittenbogaard, AC. (2014). Space-time dynamics of crime in transport nodes. Annals of the Association of American Geographers, 104(1), 131-150.

Cohen, LE, \& Felson, M. (1979). Social change and crime rate trends: a routine activity approach. American Sociological Review, 44(4), 588-608.

Grubesic, TH, \& Pridemore, WA. (2011). Alcohol outlets and clusters of violence. International Journal of Health Geographics, 10(1), Article 30.

Haberman, C.P., \& Ratcliffe, J.H. (in press). Testing for temporally nuanced relationships among potentially criminogenic places and census block street robbery counts. Criminology

Johnson, SD, Bernasco, W, Bowers, KJ, Elffers, H, Ratcliffe, J, Rengert, G, \& Townsley, M. (2007). Space-time patterns of risk: a cross national assessment of residential burglary victimization. Journal of Quantitative Criminology, 23(3), 201-219.

Newton, A, \& Hirschfield, A. (2009). Measuring violence in and around licensed premises: the need for a better evidence base. Crime Prevention and Community Safety: An International Journal, 11(3), 171-188.

Newton, A, Partridge, H, \& Gill, A. (2014). Above and below: measuring crime risk in and around underground mass transit systems. Crime Science, 3(1), 1-14.

Ratcliffe, JH. (2002). Aoristic signatures and the spatio-temporal analysis of high volume crime patterns. Journal of Quantitative Criminology, 18(1), 23-43.

Ratcliffe, JH. (2010). Crime mapping: spatial and temporal challenges. In AR Piquero \& D Weisburd (Eds.), Handbook of quantitative criminology (pp. 5-24). New York, NY: Springer.

Sherman, LW. (1995). Hot spots of crime and criminal careers of places. In JE Eck \& D Weisburd (Eds.), Crime and place. Vol. 4 (pp. 35-52). Monsey, NY: Criminal Justice Press.

Sherman, LW, Gartin, PR, \& Buerger, ME. (1989). Hot spots of predatory crime: routine activities and the criminology of place. Criminology, 27, 27.

Shiode, S, Shiode, N, Block, R, \& Block, C. (2015). Space-time characteristics of micro-scale crime occurrences: an application of a network-based space-time search window technique for crime incidents in Chicago. International Journal of Geographical Information Science. http://www.tandfonline.com/doi/abs/ 10.1080/13658816.2014.968782?.journalCode=tgis20.

Townsley, M. (2008). Visualising space time patterns in crime: the hotspot plot. Crime Patterns and Analysis, 1(1), 61-74.

Weisburd, D. (2015). The law of crime concentration and the criminology of place. Criminology, 53(2), 133-157.

\section{Submit your manuscript to a SpringerOpen ${ }^{\odot}$ journal and benefit from:}

- Convenient online submission

Rigorous peer review

- Immediate publication on acceptance

- Open access: articles freely available online

- High visibility within the field

- Retaining the copyright to your article

Submit your next manuscript at springeropen.com 